\title{
Water Local Volume Fraction on Oil in Water Dispersion
}

\author{
Siti Aslina, Hussain ${ }^{1, *}$, Xiao Y. Xu ${ }^{2}$, Geoffrey F. Hewitt ${ }^{2}$ \\ ${ }^{1}$ Department of Chemical and Environmental Engineering, Faculty of Engineering, \\ University Putra Malaysia, 43400 UPM Serdang, Selangor Darul Ehsan, Malaysia. \\ ${ }^{2}$ Department of Chemical Engineering, Imperial College London, South Kensington Campus, \\ London SW7 2AZ, UK.
}

Email: aslina@eng.upm.edu.my

(Received August 21, 2006; accepted January 9, 2008)

\begin{abstract}
The phase distribution of water-oil flows was studied experimentally from a separated flow without mixer to a oil in water or water in oil dispersed in horizontal tubes. Under most conditions the pattern was oil continuous in water dispersed or water continuous in oil dispersed flow continuously and there is entrainment in the form of drops of phase into the other. The investigations were carried out through the cross-sectional phase distribution in the flow of mixtures of water and kerosene such as EXXSOL-D80 in a horizontal $25.4 \mathrm{~mm}$ bore stainless steel section. The phase fraction distribution was determined using a traversing beam gamma densitometer, with the beam being traversed in three directions $\left(0^{\circ}, 45^{\circ}\right.$ and $90^{\circ}$ of the vertical line passing through the axis of the tube). Measurements were made at three positions spaced along the $9.7 \mathrm{~m}$ test section length $(1.0 \mathrm{~m}, 5.85 \mathrm{~m}$ and $7.72 \mathrm{~m}$ along the horizontal tube). The measurements were done in the Two-phase Oil Water Experimental Rig (TOWER) facility. This facility allows the two fluids to be fed to the test section before they are separated and returned once more to the test line. The flow developed naturally from an initial stratified flow in which the oil and water were introduced separately at the top and the bottom of the test section respectively. It was found that the liquids were fully inter-dispersed by the end of the test section. The results were also used to define the flow patterns in water-oil liquid-liquid flow system. The phase fraction distribution was shown to be homogeneously mixed near to the outlet of the test section.
\end{abstract}

Keywords: Water-oil, dispersed, phase fraction, homogeneously

$d$

$F M_{1} \quad$ flowmeter 1 for water

$F M_{2}$ flowmeter 2 for oil

$H$ total distance inside the tube, $\mathrm{m}$

I transmitted intensity of water and oil, count/s

$I_{\text {oil }} \quad$ transmitted intensity of oil, count/s

$I_{\text {wat }} \quad$ transmitted intensity of water, count/s

$N \quad$ number of counts

$V_{C W 1}$ control valve control 1 for inlet water

$V_{C W 2}$ control valve control 2 for inlet water

$V_{E} \quad$ control valve exit

$V_{\text {mix / outlet }}$ control valve control for mixture outlet

$V_{m i x / 1}$ control valve control 1 for mixture

$V_{\text {mix } / 2}$ control valve control 2 for mixture

\section{NOMENCLATURE}

$\begin{array}{ll}V_{O 1} & \text { 3-way valve } 1 \text { for oil } \\ V_{O 2} & \text { control valve } 2 \text { for oil } \\ V_{O 3} & \text { control valve } 3 \text { for oil } \\ V_{O 4} & \text { control valve } 4 \text { for oil } \\ V_{\text {O/ outlet }} & \text { control valve control for oil outlet } \\ V_{W 1} & \text { 3-way valve } 1 \text { for water } \\ V_{W 2} & \text { control valve } 2 \text { for water } \\ V_{W 3} & \text { control valve } 3 \text { for water } \\ V_{W / \text { outlet }} \text { control valve control for water outlet } \\ x_{\text {oil }} & \text { distance through the oil, m } \\ x_{\text {wat }} & \text { distance through the water, m } \\ \varepsilon_{\text {oil }} & \text { oil hold up } \\ \varepsilon_{\text {wat }} & \text { water hold up }\end{array}$




\section{INTRODUCTION}

Multiphase flow is the simultaneous flow of two or more phases in direct contact in a given system. It is important in many areas of chemical and process engineering and in the petroleum industry, e.g. in production wells and in subsea pipelines. The behavior of the flow will depend on the properties of the constituents, the flows and the geometry of the system.

There are four combinations of two-phase flows namely: gas-gas, gas-liquid, gas-solid, liquid-liquid, solid-solid and solid-liquid. Liquid-liquid flows, the subject of the present project are extremely important particularly in two-phase flow applications in horizontal pipes, for instance in the oil industry. In the oil industry, the dispersion of oil-in-water or vice versa usually appears in the oil well, to produce a fully oil in the well from offshore to onshore is one of the major problem for examples to investigate the physical of the pipe and the physical properties of the liquid that can affect the flow structure and production.

In liquid-liquid flow system, it is important to understand the nature of the interactions between the phases and to observe the ways in which the phases are distributed over the cross section of the pipe (i.e. the flow "flow regime" or "flow pattern"). In design, it is necessary to predict the flow pattern which, usually, will depend not only on the flow behavior, but also on the superficial velocities of the phases and the distribution of the fraction occupied by each phase over the cross section of the pipe. The mean in-situ volume fraction will not normally be the same as the input volume fraction. The flow behavior is also influenced by the density and viscosity of the phases and the diameter of the pipe; studies of such parametric effects include those of Charles et al. (1961), Sooth and Knudsen (1972), Martinez et al. (1988), Arirachakaran et al. (1989), Urdahl et al. (1997), Shi and Jepson (1999). Most previous studies have concentrated on general flow patterns and their delineation through flow pattern maps. There have been only a few studies focused specifically on dispersed flows in horizontal pipelines. The present detailed understanding of this phenomena involved is very limited. In the dispersed flow region, there exist two types of flow configuration, namely: oil-in-water dispersions and water-in-oil dispersions.

A number of recent studies on oil-water dispersions have focused on horizontal pipelines and, in particular, on the evaluation of the behaviour of the droplets in the system. Extensive studies of flow patterns and the transition between them have been carried out, resulting in a better understanding of the two-phase flow structure. It is important to understand the nature of the interactions between the phases and how these influence the flow patterns and the resulting flow pattern maps, the droplet behaviour and the phase distributions. Arirachakaran et al. (1989), Angeli (1996) and Soleimani (2000) found that dispersed flow for oil-water systems in horizontal pipes occurs when the liquid-liquid mixture is moving at high velocity.

In horizontal flow, the flow pattern will inevitably be more complex because the gravitational force acts perpendicular to the direction of flow. Thus, there is a tendency for the dispersed phase to move vertically (i.e. normal to the tube axis) under the influence of gravity (upwards, due to buoyancy, if the dispersed phase is the lighter phase and downwards if the dispersed phase is the heavier). This tendency is affected by the action of turbulent eddies in the continuous phase which act towards making uniform the distribution of the dispersed phase due to turbulent diffusion. The actual distribution is a manifestation of the balance between gravityinduced separation and turbulence-induced mixing.

Earlier work on liquid-liquid flows in horizontal channels included studies of the phase distribution done by Angeli (1996) and Soleimani (2000). These studies demonstrated the tendency for the dispersed phase to separate to the top or the bottom of the channel depending on its density relative to the continuous phase. The higher the velocity, the more the fluids were well mixed indicating the increasing dominance of turbulence over gravity. In these earlier experiments, the measurements were made in what was expected to be a relatively fully developed flow at the end of the test section (typically 300-400 tube diameters from the inlet). However, it seemed likely that further insight could be gained regarding the turbulent mixing and gravity separation processes by studying the development of the flow along the channel and this was the underlying theme of the work reported here.

In both the earlier case studies and in the present work, the inlet conditions were such that the heavier phase (water) was introduced at the bottom of the tube and the lighter phase (kerosene) was introduced at the top of the tube. The initial conditions were therefore of wellseparated phases though it would be expected that dispersion of the relevant phase would occur quite quickly downstream of the entrance.

\section{TOWER FACILITY SETUP}

The TOWER (Two-phase Oil Water Experimental Rig) is a liquid-liquid flow facility designed for studying flows in $25.4 \mathrm{~mm}$ (1-inch) horizontal pipes. The construction of the rig was carried out as collaboration between two previous researchers; Panagiota Angeli and Adib Kurban whose theses were published in 1996 and 1997 respectively. The TOWER facility allows the phenomena occurring during the simultaneous horizontal flow of two liquids, such as oil and water, in a pipe to be observed. The TOWER facility flow loop is illustrated in Fig. 1.

Water and oil were supplied separately from two storage tanks $0.681 \mathrm{~m}^{3}$ to the stainless steel test sections. The test section had an inside diameter of $24.3 \mathrm{~mm}$ and was made up of six successive pipe section of lengths of $1 \mathrm{~m}, 1 \mathrm{~m}$, $1.87 \mathrm{~m}, 1.87 \mathrm{~m}, 3.85 \mathrm{~m}$ and $0.11 \mathrm{~m}$ respectively, giving a total length of $9.7 \mathrm{~m}$. The pipe sections are linked together with flanged connections designed to give a continuous and smooth inner bore. The final $0.11 \mathrm{~m}$ section was made from acrylic resin to allow the flow to be observed. The mixture of the two fluids after the test section was separated in liquid-liquid separator which has $0.444 \mathrm{~m}^{3}$ horizontal vessels made from PVC reinforced with steel. It consists of a $1.94 \mathrm{~m}$ long, $0.54 \mathrm{~m}$ ID tank, containing a $0.54 \mathrm{~m}$ diameter, $0.3 \mathrm{~m}$ long Knitmesh $^{\mathrm{TM}}$ coalescer. The Knitmesh ${ }^{\mathrm{TM}}$ coalescer is fitted to promote efficient separation of the fluids and is made from filaments of two different materials: metal and plastic, knitted together. 


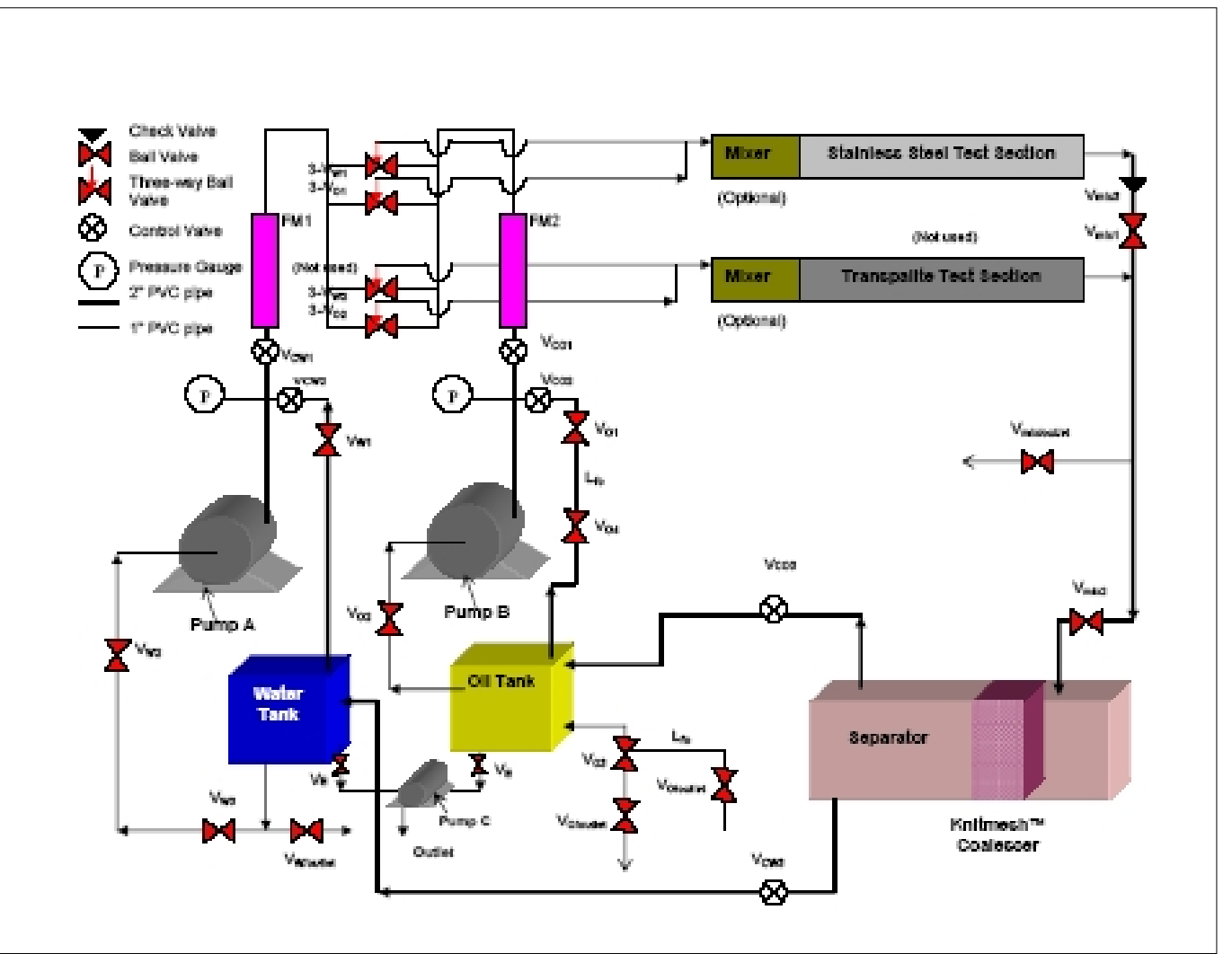

Fig 1. Two Phase Water and Oil Rig (TOWER)

These two materials are wetted by water and oil respectively and can therefore collect droplets of either fluid in a continuum of the other. The combination of different materials can also significantly improve the rate of coalescence of captured droplets which pass up or down (depending on which phase is continuous) the Knitmesh ${ }^{\mathrm{TM}}$ pad, meeting at the junction points of the two materials.

The two liquid phases used in the experiments were the water was fed directly into the water tank through a plastic hose and EXXSOL D-80 which is a clear kerosene-like oil (flash point, $75^{\circ} \mathrm{C}$, density, $801 \mathrm{~kg} / \mathrm{m}^{3}$, viscosity, $1.6 \mathrm{cp}$ at $25^{\circ} \mathrm{C}$, interfacial

tension air-oil, $0.027 \mathrm{~N} / \mathrm{m}$ and interfacial tension oilwater, $0.017 \mathrm{~N} / \mathrm{m}$ at $22^{\circ} \mathrm{C}$ ). The oil was pumped from the supply drums into the oil tank through a special branch in the suction line of the oil pump.

On the TOWER facility, previous workers have used high-frequency probes (Angeli 1996) and gamma densitometry (Soleimani 1999) for oil-water flows. There may always be ambiguities in the interpretation of results from high frequency impedance probes due to uncertainties in their detection of small droplets and, in the present work, the gamma densitometry technique was chosen. Basically, the technique involves making measurements of the attenuation of a beam of gamma rays as it passes through the test section. Calibration is achieved by making measurements of the attenuation with the pipe full of each of the pure fluids, the chordal mean phase fraction for a two-phase flow being obtained by applying a standard interpolative formula (introduced below). A detail equation of gamma densitometry and the factors influencing measurement accuracy are discussed in Wong (2003).

A gamma densitometer system has been developed by Soleimani (1999) and Siti Aslina (2004) for use on the TOWER facility. The gamma source and detector system are mounted on a motor-driven platform. The gamma source was collimated using a lead collimator to produce a mean beam of approximately $6 \mathrm{~mm}$ in diameter (Soleimani 1999, 2000). The platform was moved so that the beam traversed the tube diameter in 25 steps, each step corresponding to $1 \mathrm{~mm}$ movement. After each step, the gamma count rate was determined using the detector system over a period of 38.36 seconds as calculated from a ratio of signal total steps and with time. The platform was designed such that the beam could be traversed with the beam in the horizontal $\left(0^{0}\right)$, vertical $\left(90^{\circ}\right)$ and inclined $\left(45^{0}\right)$ orientations. At each orientation it was thus possible to obtain the water hold-up profile. Collection of these three sets of data for a given flow condition also allowed the derivation of tomographic images of phase distribution across the channel.

The gamma system consists of four subsystems which are (1) the gamma source, (2) mounting and collimator, (3) the gamma ray detection system and (4) the traversing system and data acquisition system. Gamma photons arrive at the detector after passing through the absorption media (the pipe wall and the two liquid phases). The fraction of the original photons emitted from the source, and passing through the collimator, which arrive at the detector depends on the distance passed through the absorption media and the mass absorption coefficients of the media. The number of these photons arriving at the detector per unit time is 
known as the count rate. The scanning time for each beam position is important in influencing the accuracy of the measured count rate; the longer the scanning time, the more photons arrive at the detector and the more accurate the measurement of the count rate. The hold-up of the oil $\left(\varepsilon_{\text {wat }}\right)$ and water $\left(\varepsilon_{\text {oil }}\right)$ phases in terms of the measured intensity $I$ and the full tube values $I_{\text {oil }}$ and $I_{\text {wat }}$ respectively are given below and details of the attenuation law are given in Siti Aslina (2004).

Hold-up of oil, $\quad \varepsilon_{\text {wat }}=\frac{\ln \left(I / I_{\text {oil }}\right)}{\ln \left(I_{\text {wat }} / I_{\text {oil }}\right)}$
Hold-up of water, $\varepsilon_{\text {oil }}=1-\varepsilon_{\text {wat }}$

The standard deviation of a number of counts $N$ is $\sqrt{N}$ and it follows that the relative accuracy of count rate depends on the time over which the count rate is determined. Experimentally, $I, I_{\text {oil }}$ and $I_{\text {wat }}$ were determined typically over a period of 38.36 seconds For typical conditions, the errors in $I_{o i l}, I_{\text {wat }}$ and $I$ lead to an error of around $\pm 0.26 \mathrm{~mm}$ in $x_{\text {oil }}$ and $x_{w a t}$. This corresponds to an error of around $\pm 1 \%$ in phase holdup for $x_{\text {oil }}=x_{\text {wat }}=\frac{H}{2}=\frac{d}{2}$ (i.e. at the central chord position where $H=d$, the tube diameter). The error is greater for other chordal positions and for the phase with the lower phase fractions when the phase fractions are unequal. The error measurement of phase fraction depends on the difference between the count rates for two differences cases. This measurement error is much higher in the oil-water system than an oil-air system due to the small density difference between oil and water. A relation for the error in phase hold-up in this type of measurement has been obtained based on the equation. The data measured too close to the wall (boundary layer) are not very reliable due to significant error in these regions. Temperature variation can affect the measurement error, however, in the present system, this temperature fluctuation is negligible. For each flow condition, 75 chordal mean phase fraction measurements were made ( 25 at each orientation-i.e. horizontal, vertical and $45^{\circ}$ inclined). The average phase fraction could be determined from the results at each orientation by taking the average of the chordal mean values weighted according to chord length.

For given flow conditions and axial location, the average phase fraction determined at the three respective beam orientations were in reasonable agreement. Measurements of local chordal mean phase fraction were made using the Gamma Densitometry System (GDS) at three locations ( $1.0 \mathrm{~m}, 5.85 \mathrm{~m}$ and $7.72 \mathrm{~m}$ from the inlet). The measurements were taken at four mixture velocities (i.e. $1.8 \mathrm{~m} / \mathrm{s}, 2.17 \mathrm{~m} / \mathrm{s}, 2.5 \mathrm{~m} / \mathrm{s}$ and $2.76 \mathrm{~m} / \mathrm{s}$ ) and three input water fractions (i.e. $60 \%, 46 \%$ and $40 \%$ ). This range of water fractions was chosen to span the phase inversion condition (i.e. from a water-in-oil dispersion to an oil-in-water dispersion). No specific measurements were made of the phase inversion condition in the present work but earlier work by Angeli (1996) and Soleimani (1999) these indicate that phase inversion occurs over a range $45 \%$ to $55 \%$ water cut corresponding to the velocity range of $1.8 \mathrm{~m} / \mathrm{s}$ to $2.76 \mathrm{~m} / \mathrm{s}$. The data obtained for chordal mean phase fractions could also be interpreted using a tomographic algorithm developed by $\mathrm{Hu}$ and Stewart (2002). This algorithm makes the assumption that the phase fraction distribution is symmetrical about a vertical axis passing through the centre of the tube and is implemented in a MATHEMATICA programme.

\section{RESULTS}

\subsection{The effect of inlet water fraction}

Clearly, input water fraction is a very important variable. At the lowest water fraction studied $(40 \%)$ the water would be expected to be dispersed in the oil and at the level $(60 \%)$ the oil would be expected to be dispersed in the water. Contour color stated that red as oil distributions and blue as water distribution across the cross sectional area of the pipe. In between illustrated a mixture, which is between a red and blue contour color. Tomography reveals that the phase mixing patterns are extremely complex as will be seen by examining the full set of tomographic data given in figures below. The details effect of input water fraction can be illustrated by considering four examples as follows:

\subsubsection{Mixture velocity $1.8 \mathrm{~m} / \mathrm{s}$, axial location $1.0 \mathrm{~m}$ (Fig. 2)}

At the inlet, the oil is introduced at the top of the channel and the water at the bottom. The phase distribution observed at $1.0 \mathrm{~m}$ for a mixture velocity of $1.8 \mathrm{~m} / \mathrm{s}$ (the lowest velocity studied) may strongly reflect this initial distribution with oil-rich and water-rich zones being seen at the top and bottom of the pipe on either side of a line passing vertically through the axis. Mixing on and around this line may be most intense, leading to the rather unexpected phase distribution observed.

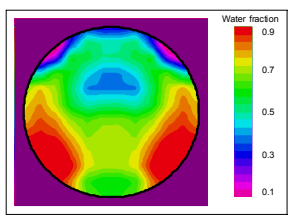

(a)

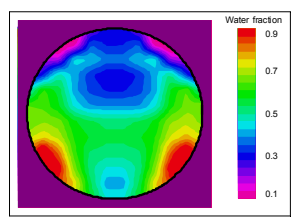

(b)

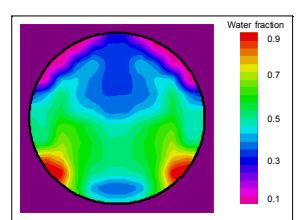

(c)
Fig. 2. Influence of input water fraction of (a) $60 \%$, (b) $46 \%$ and (c) $40 \%$ on phase distribution at a location 1.0 $\mathrm{m}$ from the inlet and for a mixture velocity of $1.8 \mathrm{~m} / \mathrm{s}$.

\subsubsection{Mixture velocity $2.76 \mathrm{~m} / \mathrm{s}$, axial location $1.0 \mathrm{~m}$ (Fig. 3)}

At the highest mixture velocity in this case, the phase distributions are more uniform, though a high concentration of water is still observed at the bottom of the pipe, and a high concentration of oil near the top of the pipe, for an input water fraction of $40 \%$ where the dispersion is water-in-oil. For $46 \%$ input water fraction, (near the expected phase inversion point) the water fraction is reasonably constant across the pipe. For $60 \%$ 
input water fraction, an oil-in-water dispersion would be expected and the oil phase concentration would be expected to be higher (as is observed) at the top of the pipe due the tendency of the (lighter) oil drops to rise upwards.

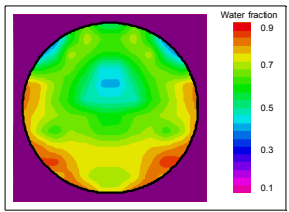

(a)

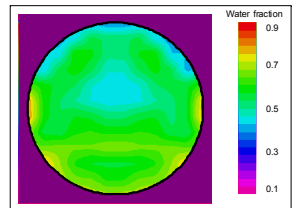

(b)

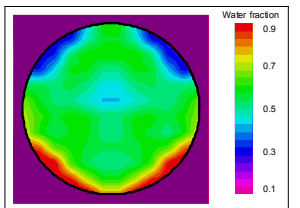

(c)
Fig. 3. Influence of input water fraction of (a) $60 \%$, (b) $46 \%$ and (c) $40 \%$ on phase distribution at a location 1.0 $\mathrm{m}$ from the inlet and for a mixture velocity of $2.76 \mathrm{~m} / \mathrm{s}$.

\subsubsection{Mixture velocity $2.17 \mathrm{~m} / \mathrm{s}$, axial location $7.72 \mathrm{~m}$ (Fig. 4)}

For this axial distance, there has been time for the two phases to partially separate with an oil "rivulet" at the top of the pipe and a water "rivulet" at the bottom of the pipe. The region between is mixed with some separation of the heavier and lighter phases observed.

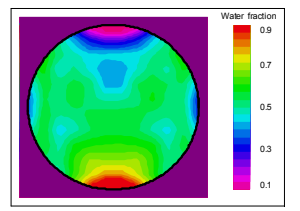

(a)

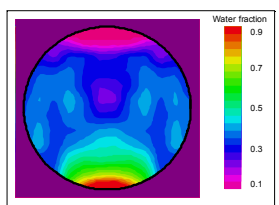

(b)

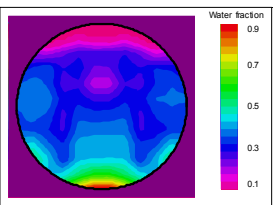

(c)
Fig. 4. Influence of input water fraction of (a) $60 \%$, (b) $46 \%$ and (c) $40 \%$ on phase distribution at a location 7.72 $\mathrm{m}$ from the inlet and for a mixture velocity of $2.17 \mathrm{~m} / \mathrm{s}$.

\subsubsection{Mixture velocity $2.5 \mathrm{~m} / \mathrm{s}$, axial location $7.72 \mathrm{~m}$ (Fig. 5)}

At this higher velocity, partial separation is also observed. However, the shape of the regions with nearpure fluid is much more complex. At $46 \%$ and $60 \%$ input water fraction, the water layer is seen to be spreading around the tube. For $40 \%$ input water fraction (water-inoil dispersion) a region of high oil concentration also appears half way along the circumference from the bottom as shown in Fig. 5(a) and (b). This is consistent with the behavior seen in stratifying annular gas-liquid flows (Badie 2000). Water is constantly separating from the core mixture and forms a downstream-draining layer near the wall which thickens near the bottom of the tube. Re-entrainment of the draining layer may occur near the wall which thickens near the bottom of the tube. Reentrainment of the draining layer may then occur preferentially from this layer, also in the region near the bottom of the tube. The explanation for the distributions seen in Fig. 5(c) is not yet clear.

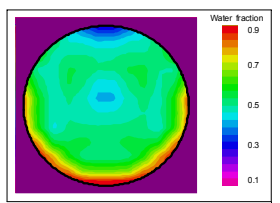

(a)

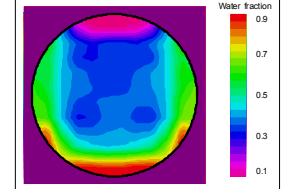

(b)

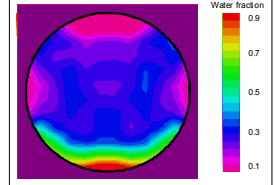

(c)
Fig. 5. Influence of input water fraction of (a) $60 \%$, (b) $46 \%$ and (c) $40 \%$ on phase distribution at a location 7.72 $\mathrm{m}$ from the inlet and for a mixture velocity of $2.5 \mathrm{~m} / \mathrm{s}$.

\subsection{The effect of mixture velocity}

The effect of mixture velocity due to the turbulence eddies appeared in the flow system, natural form flow structure, turbulence flow large eddy and based on Kelvin Helmholtz theory on phase distributions can be seen for the whole range of input water fraction and axial position in the catalogue of tomographs given in detail by Siti Aslina (2004). By considering the effect of mixture velocity at a position $7.72 \mathrm{~m}$ from the inlet for $40 \%$ input water fractions, this input water fractions correspond to water-in-oil at the highest velocity. The results are shown in Fig. 6 and demonstrate the progression from partially separated to fully mixed conditions as the velocity is increased from 1.8 to 2.76 $\mathrm{m} / \mathrm{s}$.

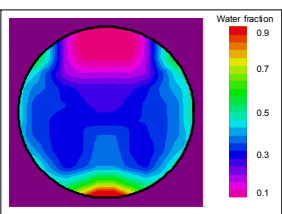

(a) $u_{m i x}, 1.8 \mathrm{~m} / \mathrm{s}$

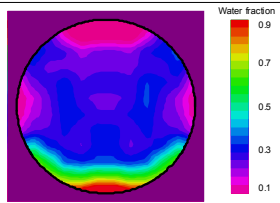

(c) $u_{m i x}, 2.5 \mathrm{~m} / \mathrm{s}$

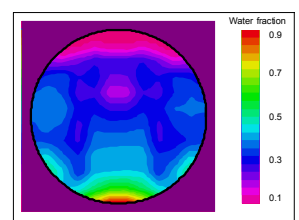

(b) $u_{m i x}, 2.17 \mathrm{~m} / \mathrm{s}$

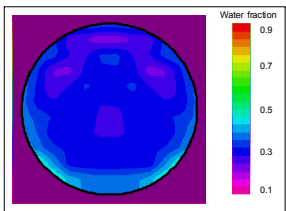

(d) $u_{m i x}, 2.76 \mathrm{~m} / \mathrm{s}$
Fig. 6. Cross-sectional phase distributions at a distance of $7.72 \mathrm{~m}$ from the inlet as a function of velocity. Input water fraction $40 \%$.

\subsection{The effect of distance from the injector}

The effects of axial position on cross-sectional phase distribution are highly complex as inspection of the full set of results as shown in Siti Aslina (2004). Here, Fig. 7 illustrated only two cases that related to those at the highest velocity as follows: 
(1) The effect of axial positions for a mixture velocity of $2.76 \mathrm{~m} / \mathrm{s}$ and an input water fraction of $40 \%$. At 1.0 $\mathrm{m}$ from the inlet, the distribution reflects the input phase separation and at $5.85 \mathrm{~m}$, "rivulets" of oil and water are seen at the top and bottom of the pipe respectively. However, by $7.72 \mathrm{~m}$, the phase distribution is relatively uniform.

(2) The effect of axial position for a mixture velocity of $2.76 \mathrm{~m} / \mathrm{s}$ and input water fraction of $60 \%$ (Fig. 7). Here, for the oil-in-water dispersion, more rapid mixing occurs near the inlet $(1.0 \mathrm{~m})$ but, again, "rivulet" separation occurs further down the tube $(5.85 \mathrm{~m})$. These rivulets are then eroded away to give relatively uniform phase distribution at a distance of $7.72 \mathrm{~m}$.

Generally Fig. 7 indicated that there is a tendency for the phases to mix as they pass along the channel. $\mathrm{P}_{\mathrm{GDS}}$ as shown in Fig. 7 is a position of the Gamma Densitometer System located on the horizontal pipeline.

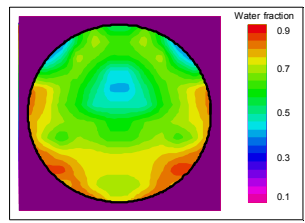

(a) $P_{G D S}, 1.0 \mathrm{~m}$

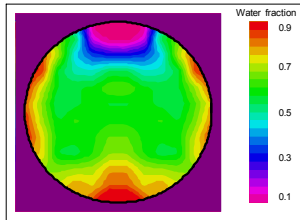

(b) $P_{G D S}, \quad 5.85 \mathrm{~m}$

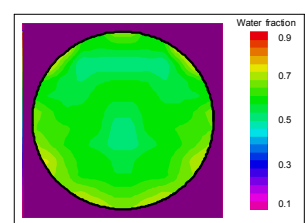

(c) $P_{G D S}, 7.72 \mathrm{~m}$
Fig. 7. Effect of axial position on cross sectional phase distribution for a mixture velocity of $2.76 \mathrm{~m} / \mathrm{s}$ and an input water fraction of $60 \%$.

\section{COMPARISON OF LOCAL VOLUME FRACTION RESULTS WITH PREVIOUS STUDIES}

Measurements of the vertical distributions of chordal mean void fraction were made by Soleimani (1999) for conditions similar to those, used in the present experiments. Comparisons between the present data and that reported by Soleimani (1999) are shown in Fig. 8 and 9 . For the highest velocity $(2.76 \mathrm{~m} / \mathrm{s}$ for the data reported here and $3.0 \mathrm{~m} / \mathrm{s}$ for the data of Soleimani, 1999), there is reasonable qualitative agreement between the two data sets. However, for the lower velocity $(2.12$ $\mathrm{m} / \mathrm{s}$ in the data of Soleimani (1999) and $2.17 \mathrm{~m} / \mathrm{s}$ in the data reported here), the present data show greater phase separation with lower water concentration at the top of the pipe and higher at the bottom. This is probably accounted for by the fact that Soleimani (1999) used a static mixer immediately downstream of the inlet.

\section{CONCLUSIONS}

The experimental results presented above serve mainly to illustrate the complexity of the processes in liquidliquid flows. If we regard flow pattern as a characteristic type of phase distribution then it will be seen that this
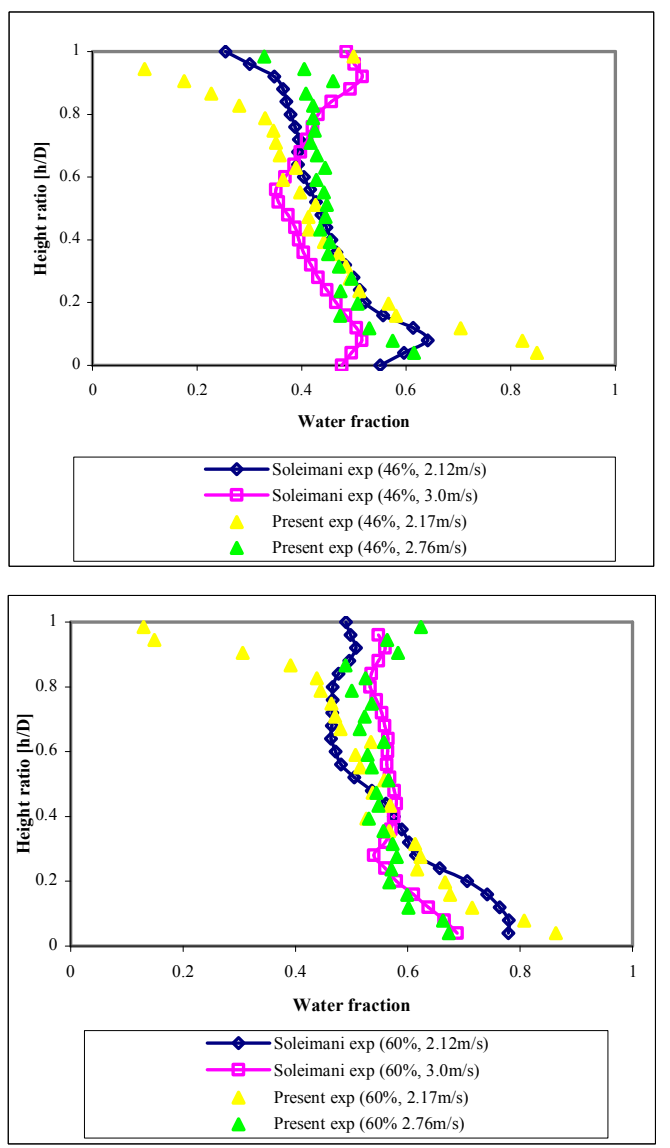

Fig. 8. A plot of comparison of present data for vertical distribution of water phase fraction across the cross section for an input water fraction of $46 \%$ and $60 \%$ at $7.72 \mathrm{~m}$ from the inlet with that of Soleimani, 1999.

depends not only on phase flows but also on the axial position.

The pressure gradient passes through a maximum with distance before becoming relatively independent of distance towards the end of the pipe. This may reflect energy losses associated with intense mixing near the inlet. At high enough mixture velocities, the phases ultimately became mixed (dispersion of water in oil or oil in water), but this is achieved only slowly. The most important experimental results obtained in the present work described those for cross-sectional phase fraction distributions obtained using gamma tomography. The effect of axial position show the tendency of the phase to mix and approach uniform distribution as the flow proceeds along the channel are the key of results as depicted in Fig. 7. In general, the tomography results illustrate the great complexity of liquid-liquid dispersed flows, reflecting the many competing processes (turbulence, gravitational separation, droplet break-up and coalescence) which are occurring in the channel.

\section{ACKNOWLEDGEMENTS}

Siti Aslina Hussain wishes to acknowledge with grateful thanks the sponsorship of Malaysia Government, Universiti Putra Malaysia, for the research grant. Also, many thanks to Professor John Heggs on his peer review to this paper. 


\section{REFERENCES}

Angeli, P. (1996). Liquid-liquid in Horizontal Pipes. $\mathrm{PhD}$ Thesis, Imperial College London, UK.

Angeli, P and G.F. Hewitt (2000). Flow Structure in Horizontal Oil-Water Flow. International Journal Multiphase Flow (26), 1117-1140.

Arirachakaran, S., K.D. Oglesby, M.S. Malinowsky, O. Shoham and J.P. Brill (1989). An Analysis of Oil/Water Flow Phenomena in Horizontal Pipes. SPE paper 18836, SPE Prod. Operating Symposium, 155-167, Oklahoma, March 13-14.

Badie, S. (2000). Horizontal Stratifying/Annular GasLiquid Flow. PhD Thesis, Imperial College London, UK.

Charles, M.E., G.W. Govier and G.W. Hodgson (1961). The Horizontal Pipeline Flow of Equal Density OilWater Mixture. Canadian Journal Chem. Engineering (39), 27-36.

Gilmore, G and J.D. Hemingway (1995). Practical Gamma-ray Spectrometry Handbook, McGrawHill, New York.

Hu, B and C. Stewart (2002). XrayCT 1.1 Calculation Principle and User's Manual. Three Plex Project, MPS/188, Department of Chemical Engineering and Chemical Technology, Imperial College of Science, Technology \& Medicine, London, England.

Kurban, A.P.A, M.A. Mendes-Tatsis and G.F. Hewitt (1995). Oil-Water Flows in Horizontal Tubes. The 1995 IChemE Research Event/ First European Conference, 757-759.

Martinez, A.E, S. Arirachakaran and J.P. Brill (1988). Prediction of Dispersion Viscosity of Oil/Water Flow in Horizontal Pipes. SPE 18221, 427-437.

Rashmi, W., Siti Aslina, H. and Thomas, C.Y.S (2006). Analysing Liquid Holdup for Dispersed Flow using $C F D, 11^{\text {th }}$ Asian Pacific Confederation of Chemical Engineering (APCChE Congress 2006), Kuala Lumpur.

Rashmi, W., Siti Aslina, H. and Thomas, C.Y.S. (2006) CFD for Liquid-liquid Dispersed Flows in Horizontal Pipe. Seminar on Engineering and Technology (SET 2006). Kuala Lumpur, 208-211.

Shi, H., J.Y. Cai and W.P. Jepson (1999). Oil-Water Distributions in Large Diameter Horizontal Pipelines. Multiphase flow and Heat transfer, Proc. of the Fourth International Symposium, Xi'an China, 73-80.

Siti Aslina, H. (2004). Experimental and Computational Studies of Liquid-Liquid Dispersed Flows. PhD Thesis, Imperial College London, UK.

Siti Aslina, H. (2006). Local Volume Fraction on Liquidliquid Dispersion, Proceedings: The Eleventh Asian Congress of Fluid Mechanics, 434-443.
Siti Aslina, H., Siti Mazlina, M. K. and Wan Hassan, M.J. (2006). In-Situ Phase Fractions for Oil and Water Occupied in Pipe Channel. International Journal of Engineering and Technology. (3) 2. 248256

Soleimani, A. (1999). Phase Distribution and Associated Phenomena in Oil-Water Lows in Horizontal Tubes. $\mathrm{PhD}$ Thesis, Imperial College London, UK.

Soleimani, A. (2000). Spatial Distribution of Oil and Water in Horizontal Pipe Flow. SPE Journal, (4)5, 394-401.

Sooth, P.M. and J.G. Knudsen (1972). Two-Phase Liquid-liquid Flow in Pipes. AIChE Symposium Series (68)118, 38-44.

Urdahl, O., A.O. Fredheim and K. Loken (1997). Viscosity Measurements of Water-in-Oil Emulsions Under Flowing Conditions: A Theoretical and Practical Approach. Colloids and Surfaces Journal, (8) 623-634.

Wong, W-L. (2003). Flow Development of Mixing in Three Phase Slug Flow, PhD Thesis, Imperial College London, UK. 